\title{
Developing a Conceptual Model of influences around Integrated Reporting, New Insights, and Directions for Future Research
}

\author{
Charl de Villiers \\ The University of Auckland, and University of Pretoria \\ Pei-Chi Kelly Hsiao \\ The University of Auckland \\ Warren Maroun \\ University of the Witwatersrand
}

Please cite as:

De Villiers, C., Hsiao, P.-C.K. \& Maroun, W. 2017. Developing a Conceptual Model of influences around Integrated Reporting, New Insights, and Directions for Future Research, Meditari Accountancy Research, 25(4), 450-460.

\begin{abstract}
Purpose:

This article develops a conceptual model for examining the development of integrated reporting, relates the articles in this Meditari Accountancy Research special issue on integrated reporting to the model, and identifies areas for future research.
\end{abstract}

\section{Design/methodology/approach:}

The article uses a narrative/discursive style to summarise key findings from the articles in the special issue and develop a normative research agenda.

\section{Findings:}

The findings of the prior literature, as well as the articles in this special issue, support the conceptual model developed in this article. This new conceptual model can be used in multiple ways.

\section{Originality/value:}

The special issue draws on some of the latest developments on integrated reporting from multiple jurisdictions. Different theoretical frameworks and methodologies, coupled with primary evidence on integrated reporting experience, construct a pluralistic assessment of integrated reporting which can be used as a basis for future research. The new conceptual model developed in this article can be used as an organizing framework, a way of understanding and thinking about the various influences, a way of identifying additional factors to control for in a study, and/or a way to identify new, interesting, and underexplored research questions.

\section{Acknowledgements}

The authors thank the authors and reviewers of the articles in this special issue, as well as the reviewers of this lead article of the special issue, for their hard work and insightful comments. 


\section{Introduction}

Integrated reporting (IR) started in practice in the early years of the millennium. It was a response to the global financial crisis and string of corporate failures which undermined confidence in conventional financial statements and highlighted the limitation of retrospective reporting on a single measure of organisational performance (IIRC, 2013). The weaknesses in sustainability reporting were also relevant. Traditional sustainability reports presented environmental, social and governance (ESG) disclosures separately from financial information and did not always explain the interconnection between strategy, risks and the multiple forms of capital under an organisation's control (De Villiers et al., 2014, 2017).

In this context, IR represented an evolution of the provision of social environmental and financial information in a format where the different kinds of disclosures are interconnected (De Villiers et al., 2014, 2017; Solomon and Maroun, 2012). Grounded in an integrated thinking philosophy, IR can be seen as a call for transparent and responsible business management and reporting, aiming to provide better quality information that explains the interconnection between social, environmental, and economic dimensions of an organisation, to improve the quality of information provided to stakeholders and to promote sustainable business practices (Maroun and De Villiers, 2017).

Arguably, the beginning of IR can be traced to the release of King-I in 1994. King-I was developed in South Africa in response to the need to establish the credibility of the local capital market and provide a stakeholder-centric model for holding companies accountable for their performance. It was followed by the release of King-II in 2002, which firmly established the idea of reporting on social, environmental and economic activity and South Africa's leading role in corporate governance and reporting (De Villiers et al., 2014; Dumay et al., 2016). In 2009, King-III called for the preparation of an integrated report, which provides "a holistic and integrated representation of the company's performance in terms of both its finance and its sustainability" (IOD, 2009). In 2010, South Africa became the first jurisdiction to require listed companies to prepare an integrated report on a complyor-explain basis, with the first discussion paper outlining the elements of an integrated report published in 2011 (IRCSA, 2011).

A number of important developments were taking place in the UK and the USA at roughly the same time. In September 2009, Sir Michael Peat (of the Prince of Wales' Accounting for Sustainability Project (A4S)), Paul Druckman (of the Global Reporting Initiative (GRI)) and Mervyn King (after whom South African codes of corporate governance are named) met in London to discuss how to integrate the multiple types of reports typically produced by large organisations (Dumay et al., 2016). During 2010, Harvard-based academics presented their views on IR as a means of explaining the impact of financial and non-financial resources on each other (Eccles and Krzus, 2010; Eccles and Serafeim, 2014). The International Integrated Reporting Committee, later renamed the International Integrated Reporting Council (IIRC), was formed in 2010 and issued the first international framework on IR in 2013 (see IIRC, 2013).

The objective of IR can be summarised as:

IR "promotes a more cohesive and efficient approach to corporate reporting and aims to improve the quality of information available to providers of financial capital to enable a 
more efficient and productive allocation of capital... The primary purpose of an integrated report is to explain to providers of financial capital how an organization creates value over time." (IIRC, 2013, p.4)

Preparing a high quality integrated report has proven challenging. Repetition and generic disclosures undermine the value relevance of the reports (Solomon and Maroun, 2012). Companies have struggled to report clearly on their strategy, risks and the management of non-financial capitals (PwC, 2015). The connection between what organisations report and how they are actually managed/operated has also been questioned (Brown and Dillard, 2014; Stubbs and Higgins, 2014). Perhaps most significant is the fact that IR remains focused on the providers of financial capital, leading critiques that IR lacks a commitment to genuine accountability and sustainability (Milne and Gray, 2013; Flower, 2015).

This article does not debate the merit of these criticisms or the change potential of IR. Instead, the article focuses on constructing a conceptual model to frame the IR research that has emergence. The large and expanding body of IR research can be presented in a more coherent fashion with this model as the organising frame. The development of the model is discussed in the next section.

\section{A conceptual model of influences around Integrated Reporting}

Figure 1 presents a conceptual model of the overall IR process. This model is general in nature and finds its origins in one of the ways accounting researchers have traditionally conceptualized research on reporting: in terms of determinants of certain accounting choices and their consequences (Alrazi et al., 2015; De Villiers and Maroun, 2017). The model is based on the IR literature and includes the IIRC's and users' internal processes.

Overall, the model: (1) identifies potential determinants of IR, (2) acknowledges the IIRC's processes and influences, (3) reflects organisation's IR process, (3) shows the potential effect of IR and external use of integrated reports, and (4) identifies possible consequences arising from IR. The arrows in the model show the direction of the main causal effects. However, causation may run in the reverse direction, such as report users influencing report preparers under certain circumstances. The concepts within each box can also influence each other. For example, within the report preparers' box, integrated thinking may lead to stakeholder engagement, which may influence the management control systems chosen to support the integrated report that is published, which may in turn lead to assurance of the integrated report. However, the assurance process can influence the management control systems through the insistence of assurance providers on 'auditable' evidence. Some of the relationships in the model are based on the IIRC's stated advantages of IR and some on theory, while others have been backed up by empirical evidence. As IR is an emerging field, the model is expected to evolve as new empirical evidence moves our current patchwork of knowledge to more solid and shared understandings. 


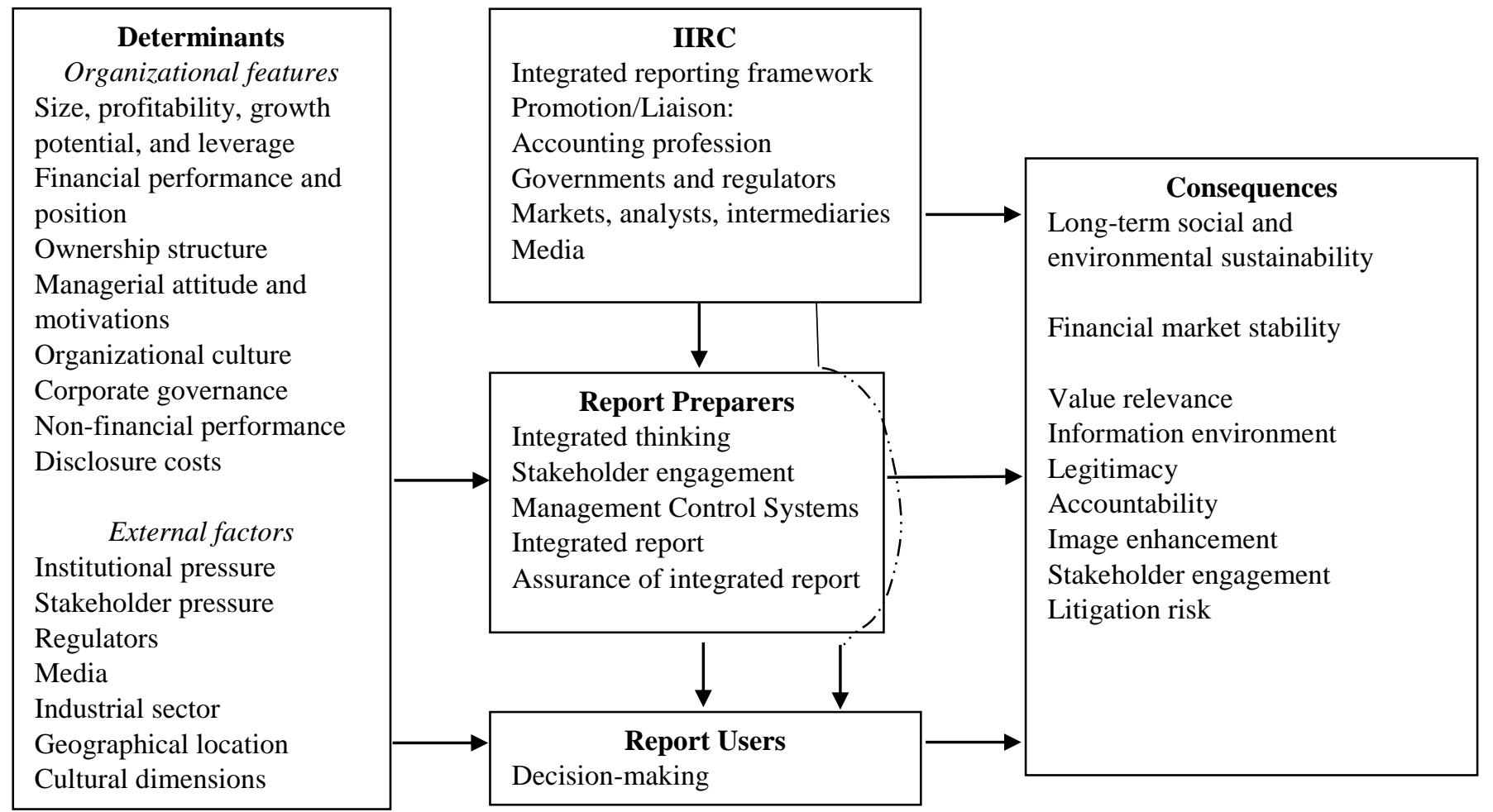

Figure 1. Conceptual model of influences around Integrated Reporting

\section{Backing for the Conceptual model for Integrated Reporting from the literature}

Academic research have investigated various aspects of IR, providing initial evidence on aspects related to motivation and determinants, IIRC processes, internal changes and institutionalization, assurance practices, quality of integrated reports, how report users deal with IR, and the various consequences of IR.

\section{Determinants}

Institutional pressure, stakeholder pressure, and the strengthening of corporate legitimacy or reputation have been common themes researchers explored as determinants of IR. For instance, Higgins et al. (2014) find managers consider it is inevitable to adopt IR regardless of its value. Due to the pressure from peer reporting practices and stakeholder expectations regarding corporate transparency, reporting managers face pressure from both top management and external stakeholders to prepare an integrated report. Lueg et al. (2016) provide supporting evidence as their study finds external pressures driven by demands from shareholders, local authorities, employees, and customers lead to the eventual preparation of integrated disclosures for a case study company. Studies by Steyn (2014) and Lodhia (2015) suggest managers commonly associate IR with advancements in corporate reputation, improvements stakeholder relationships, and reduction in reputation risk. Furthermore, managers may engage in IR with the intention of impression management (Melloni et al., 2016).

While there are motivations for engaging in IR, corporate confidentiality and proprietary costs are examples of factors that may deter managers from preparing an integrated report. The disclosure of forward-looking and strategic information in accordance with the IIRC Framework is commonly viewed as an additional reporting burden and unnecessary exposure to increased litigation risk 
(Perego et al., 2016). Furthermore, it is challenging to disclose material information without compromising business confidentiality (Steyn, 2014).

Preliminary quantitative IR studies evidence that institutional and cultural factors influence the adoption of IR; for instance, looking at the influences of a country's legal system or cultural dimensions on disclosing an integrated report (Frías-Aceituno et al., 2013, García-Sánchez et al., 2013). It is common for archival studies to investigate or control for a range of variables that may influence the decision to produce an integrated report, such as firm size, profitability, corporate governance characteristics, and non-financial performance (e.g., Fasan and Mio, 2016, Lai et al., 2016).

\section{IIRC}

Humphrey et al. (2017) explore the processes used by the IIRC to promote and institutionalize IR, dealing with several of the concepts in the IIRC box of the conceptual model in Figure 1. Some academics have shown concerns over IIRC and proponents of IR promoting the IIRC Framework as a business case. Brown and Dillard (2014) and Milne and Gray (2013) suggest it is unlikely for IR to stimulate substantial changes in organizational operations as the promotion of IR as a business case encourages stakeholder management rather than accountability to stakeholders. Similarly, Flower (2015) argues the IIRC's leniency towards corporate needs and the discretion left to management in preparing an integrated report will result in little change in current reporting practices.

\section{Report preparers}

Studies suggest that the implementation of IR results in stronger internal communications by breaking down the barriers between departments and stimulating strategic dialogue between financial and non-financial teams. In addition to strengthening collaboration between units, IR helps clarify the value creation path for each internal function and act as a communication tool for functions to present itself to upper level management (Mio et al., 2016). However, there is also evidence that suggests IR has little impact on internal operations. Higgins et al. (2014) and Stubbs and Higgins (2014) find adopters consider IR practices an extension of sustainability reporting. Integrated reports are more about story-telling and meeting institutional expectations, and IR does not stimulate radical changes or innovations in reporting processes in the initial stages of adoption. Adams (2017) finds that some directors are sceptical of the changes that IR possibly brings to organizational operations. There are instances of fake integrated reports as corporations may fail to engage in the IR process and still label their report as 'integrated' even when it contains disintegrated information.

Implementation of IR requires managers to engage in integrated thinking, and develop new ways of measuring, managing, and disclosing information. Parrot and Tierney (2012) find a challenge in IR lies in making non-financial teams quantitative and measurable, this relates to addressing difficulties in measuring and identifying trade-offs between capitals, and balancing multiple stakeholder interests. Despite these challenges, Parrot and Tierney (2012) find managers consider IR practices and stakeholder engagement as fundamental factors to the case company's success, suggesting the maximization of long-term value requires addressing ethical and relational concerns.

\section{Report users}

There has been criticisms of the contents or quality of integrated reports. For instance, Atkins and Maroun (2015) find that while South African institutional investors consider integrated reports an improvement from traditional annual reports, reports are often criticised for excessive repetition and for following a box-ticking approach. Haji and Anifowose (2016) argue that IR is more ceremonial 
than substantive, where the process has not brought about major changes in how corporations connect financial and non-financial information. However, Haji and Anifowose (2016) find corporations are disclosing a higher level of unfavourable information and are recognising interrelationships between capitals. Doni et al. (2016) suggest there are problems with comparability across reporting organizations due to a diversity in the type and quality of information disclosed in integrated reports.

\section{Consequences}

Emerging IR archival studies have investigated the relationship between IR and market reactions. Knauer and Serafeim (2014) and Serafeim (2015) suggest greater corporate transparency and initiatives that enhance sustainability performance attracts long-term investors. These studies find integrated thinking and reporting practices change the investor base of a company, where the growth in long-term investor base subsequently contributes to stronger economic performance. Barth et al. (2017) provide evidence suggesting IR practices results in economic benefits. The study finds an association between higher quality integrated reports and lower bid-ask spreads, higher firm value and greater expected cash flows. Similarly, Lee and Yeo (2016) support this finding and identify that organizational complexity and external financing needs strengthens this relationship. Zhou et al. (2017) find that a higher level of alignment between reports and the IIRC Framework is associated with lower analyst forecast error. The study suggests greater alignment with the Framework leads to reductions in cost of equity capital and greater market returns.

\section{Contributions of this special issue to our understanding of the Conceptual model for Integrated Reporting}

This special issue contributes to the developing field of IR, fostering further research and debate into this reporting phenomenon. The ten articles in this special issue examine IR from a practical perspective, focusing on different parts of the new conceptual model for IR. This special issue provides new insights into several of the aspects in the model, including the black box of the IR implementation process and internalization, and assesses the usefulness of integrated reports from users' perspectives. Further understanding of IR from both preparers' and users' viewpoints supports better understandings of the determinants and consequences of IR.

Dumay et al. (2017) address several of the aspects of the conceptual model, including the IIRC and preparers boxes. Dumay et al. (2017) assess the possible barriers and potential success of the IIRC Framework from an academic perspective, raising questions of legitimacy. The study draws upon the IR literature and various documents, suggesting areas for improvement in academic research on IR, and the need for contributions to policy and practice.

\section{Report preparers}

McNally et al. (2017) and Del Baldo (2017) explore the challenges of preparing an integrated report. McNally et al. (2017) highlight the difficulties managers encounter when expanding and developing existing accounting systems to collect new types of data. IR is driven by compliance and managers remain under pressure to deliver short-term returns for market participants. Management systems are developing to facilitate the IR process, but data are often compiled manually on an ad hoc basis, which undermines the accuracy and reliability of the data. Rather than engaging in integrated thinking, report contents are based on disclosure requirements, the code of best practice, or competitors' disclosures. IR has not resulted in radical changes in managers' mind-sets (see also 
Higgins et al., 2014; Stubbs and Higgins, 2014). They perceive the usefulness of integrated reports is limited because the investor community remain focused on financial statements.

Offering perspectives from another organisational type, small and medium enterprises (SMEs), Del Baldo (2017) investigates the usability of the IIRC Framework based on a case study. Del Baldo (2017) identifies challenges regarding the assessment of non-financial information, which slowed down the reporting process. As SMEs are characterized by a culture of weak accountability and lacking management and performance control systems, it is difficult to implement more sophisticated forms of reporting such as IR. This challenge is mitigated though managerial commitment and leadership, the appointment of a coordination manager, use of external consultancy, and direct involvement with peers involved in IR. Furthermore, the study identifies perceived internal and external benefits associated with IR adoption and suggests how the IIRC Framework can be made user-friendly for SMEs.

Another paper that provides insights into the reporting process is Lai et al. (2017), which document how managers determine the concept of materiality and the users of integrated reports. From indepth interviews with report preparers and drawing on the theory of institutional reality, Lai et al. (2017) document that materiality is determined by continuous interaction among the board, management and report users. Managers in the case company subjectively assigned materiality to the meaning of strategy. The contents of the integrated report is determined by the strategy team, with top management driving the focus of the reports. Capital providers are seen as the primary audience for integrated reports, and reports are also intended for communication with current and potential employees.

Guthrie et al. (2017) and Dumay and Dai (2017) focus on integrated thinking and internal changes. Guthrie et al. (2017) involve the public sector, detailing the processes organizations employ to facilitate the adoption of the IIRC Framework. The paper analyses changes in internal structures and processes following the introduction of the Framework. Guthrie et al. (2017) find that despite starting the IR journey from sustainability reporting, IR is linked with strategy and value creation. While the adoption of the IIRC Framework has led to integrated thinking, the change is incremental rather than a revolutionary change.

Dumay and Dai (2017) reach a similar conclusion regarding the impact of IR on internal changes. The case study examines the impact of integrated thinking as an organizational cultural control. They find that while IR provided a clearer direction for reporting and helped managers discover limitations with their strategic plans, the process does not affect the day-to-day operations of employees. Additionally, managers hold opposing views regarding whether integrated thinking improves communication and facilitates the breaking down of organizational silos. For companies developing a long-term approach, the existing culture is embedded in the organization and IR is not expected to influence culture. The paper concludes that integrated thinking as a cultural control appears limited.

Macias and Farfan-Lievano (2017) examine the implementation of the IIRC Framework in the context of an emerging economy, conducting multiple case studies of Colombian enterprises. The paper identifies the relationship between value creation and the use of the IIRC Framework, and presents limitations to IR. Macias and Farfan-Lievano (2017) suggest IR contributes to value creation by enhancing reputation and corporate legitimacy, resulting in greater market 
competitiveness. Integrated reports are not communicating information for broad groups of stakeholders, but are more focused on communicating economic sustainability and at times provide insufficient material. The study finds the IIRC Framework is complementary to the Global Reporting Initiative guidelines.

\section{Report users}

Du Toit (2017) assesses the readability of integrated reports, presenting new findings on IR practice from the perspective of users. The study finds integrated reports are considered 'difficult material', suggesting reports generally lack readability and may be largely unreadable by individuals without a tertiary qualification. Following this finding, Du Toit (2017) questions the usefulness of integrated reports for enhancing legitimacy or for impression management purposes, as only a small proportion of the intended audience may find it readable. The study also finds a positive correlation between complex language and higher quality integrated reports, as assessed by a Big 4 accounting firm.

Du Toit et al. (2017) assess the development of content of social, environmental, and ethical information disclosed in integrated reports over time. The analysis shows a reduction in the amount of disclosure, which excludes important pieces of information. The study concludes that a reduction in information does not enhance quality, and it is suggested that disclosure quality may be improved by not restricting certain types of information into specific sections. Du Toit et al. (2017) suggest managers struggle to improve the quality of integrated reports and further guidelines on reporting requirements may be needed.

\section{Consequences}

Silvestri et al. (2017) develop a research framework that enables assessment whether IR is used as a strong or weak accountability tool. The framework is based on three dimensions: stakeholder involvement, communication of value creation process though the business model, and integration of financial and non-financial reports. Adoption of a strong or weak accountability perspective is judged by the position of the organization on each of the dimensions. Silvestri et al. (2017) apply the framework to a case study and assesses the entity as providing a medium degree of accountability.

\section{Conclusion and directions for future research on Integrated Reporting}

This article develops a new conceptual model that depicts the influences and causal links around IR, shown in Figure 1. The model is based on the benefits proposed by the IIRC, theoretical links, and evidence provided by the emerging IR literature. This literature is discussed and lined to the conceptual model before proceeding to a discussion of the new insights provided by the articles published in the current special issue of Meditari Accountancy Research.

The conceptual model provides a starting point for thinking about the various influences and causal relationships that shape IR. As such, researchers will find the model useful to identify new research questions and to develop the research design of such studies. The model could provide the impetus for researchers to question current understanding by setting out to find evidence that refute the assumptions of the model and present new empirical evidence. This process of presenting evidence to support the model, as well as evidence to modify or refute parts of the model, will contribute to improved understandings of causes and consequences of IR. 
We start the process of identifying opportunities for future IR research by systematically working through the model from left to right and from top to bottom. The determinants box in the model refers to several organizational features and several external factors. While the prior literature already provides evidence of the link between some of these features and factors and IR, these could also influence users' expectations and reactions to integrated reports. In addition, organizational features and external factors could influence each other while influencing IR and users. For example, a caustic organizational culture could lead to negative media attention, which could in turn lead to increased stakeholder pressure to provide better quality IR information. This sequence of causal relationships can also lead to increased expectations among the users of reports, which could influence the way users interpret the integrated reports in their decision-making processes. These posited links are, at present, poorly understood and empirical evidence should be welcomed. At the same time, this example of the links within and between the boxes in the model demonstrates that there are many more causal links than arrows in the model.

Moving now to the IIRC box in the model, although evidence has started to emerge regarding the processes whereby the IIRC seek to influence and promote IR (Humphrey et al., 2017), the IIRC's activities are ongoing and the field of IR is developing. Further evidence of the activities of the IIRC and how these influence other boxes could provide fruitful avenues for future research. For instance, studying the influence of the IIRC's media engagement on the acceptance of IR among financial intermediaries. Another example is how the IIRC's collective activities influence IR adopting organizations, the users of integrated reports, and the ability of IR to lead to positive economic and other consequences.

The links between the concepts mentioned within the report preparers' box are starting to be explored and will, no doubt, provide many more opportunities for future research. For example, how does integrated thinking influence stakeholder engagement, management control systems, integrated reports, and/or the likelihood and scope of assurance over the integrated report? How does assurance influence management control systems and stakeholder engagement? In addition to these questions that relate to causality within the report preparers' box, questions could be (and have been) asked about the influence of each concept on users and on consequences. As such, each of the concepts in the preparers' box can be linked with each of the concepts in the consequences box, and all these concepts can be measured in different ways, leading to multiple potential research projects. As one example of a concept that can be measured in several ways, take the concept of value relevance, which can be measured, among other ways, with reference to market value, Tobin's Q, future cash flows, expected future cash flows, future earnings, expected future earnings, average cost of capital, cost of equity capital, and cost of debt. In turn, several of these concepts can be measured in different ways.

Overall, the conceptual model proposed in this article can be used as an organizing framework, a way of understanding and thinking about the various influences, a way of identifying additional factors to control for in a study, and/or a way to identify new, interesting, and underexplored research questions. 


\section{References}

Adams, C. A. (2017), "Conceptualising the contemporary corporate value creation process", Accounting, Auditing \& Accountability Journal, Vol. 30 No. 4, pp. 906-931.

Alrazi, B., De Villiers, C. and van Staden, C. J. (2015), "A comprehensive literature review on, and the construction of a framework for, environmental legitimacy, accountability and proactivity", Journal of Cleaner Production, Vol. 102, pp. 44-57.

Atkins, J. and Maroun, W. (2015), "Integrated reporting in South Africa in 2012: Perspectives from South African institutional investors", Meditari Accountancy Research, Vol. 23 No. 2, pp. 197-221.

Barth, M. E., Cahan, S. F., Chen, L. and Venter, E. R. (2017), "The Economic Consequences Associated with Integrated Report Quality: Early Evidence from a Mandatory Setting". Available from: https://ssrn.com/abstract=269940

Brown, J. and Dillard, J. (2014), "Integrated reporting: On the need for broadening out and opening up", Accounting, Auditing \& Accountability Journal, Vol. 27 No. 7, pp. 1120-1156.

De Villiers, C. and Maroun, W. 2017. Sustainability Accounting and Integrated Reporting, Oxfordshire, UK, Routledge.

De Villiers, C., Rinaldi, L. and Unerman, J. (2014), "Integrated Reporting: Insights, gaps and an agenda for future research", Accounting, Auditing \& Accountability Journal, Vol. 27 No. 7, pp. 1042-1067.

De Villiers, C., Venter, E. R. and Hsiao, P.-C. K. (2017), "Integrated reporting: background, measurement issues, approaches and an agenda for future research", Accounting \& Finance, advance online publication. doi: 10.1111/acfi.12246.

Del Baldo, M. (2017), "The Implementation of Integrating Reporting in SMEs: Insights from a pioneering experience in Italy", Meditari Accountancy Research, Vol. 25 No. 4.

Doni, F., Gasperini, A. and Pavone, P. (2016), "Early adopters of integrated reporting: The case of the mining industry in South Africa", African Journal of Business Management, Vol. 10 No. 9, pp. 187-208.

Du Toit, E. (2017), "The readability of integrated reports", Meditari Accountancy Research, Vol. 25 No. 4.

Du Toit, E., van Zyl, R. and Schutte, G. (2017), "Integrated reporting by South African companies: a case study", Meditari Accountancy Research, Vol. 25 No. 4.

Dumay, J., Bernardi, C., Guthrie, J. and Demartini, P. (2016), "Integrated reporting: A structured literature review", Accounting Forum, Vol. 40 No. 3, pp. 166-185.

Dumay, J. and Dai, T. (2017), "Integrated thinking as a cultural control?", Meditari Accountancy Research, Vol. 25 No. 4.

Dumay, J., Guthrie, J. and La Torre, M. (2017), "Barriers to Implementing the International Integrated Reporting Framework: A Contemporary Academic Perspective", Meditari Accountancy Research, Vol. 25 No. 4.

Eccles, R. G. and Krzus, M. (2010), One Report : Integrated Reporting for a Sustainable Strategy, John Wiley \& Sons, Hoboken, NJ, USA.

Eccles, R. G. and Serafeim, G. 2014. Corporate and Integrated Reporting: A Functional Perspective. Harvard Business School, 1 (1).

Fasan, M. and Mio, C. (2016), "Fostering stakeholder engagement: The role of materiality disclosure in integrated reporting", Business Strategy and the Environment, Vol.26 No. 3, pp. 288-305.

Flower, J. (2015), "The International Integrated Reporting Council: A story of failure", Critical Perspectives on Accounting, Vol. 27, pp. 1-17.

Frías-Aceituno, J. V., Rodríguez-Ariza, L. and Garcia-Sánchez, I. M. (2013), "Is integrated reporting determined by a country's legal system? An exploratory study", Journal of Cleaner Production, Vol. 44, pp. 45-55. 
García-Sánchez, I.-M., Rodríguez-Ariza, L. and Frías-Aceituno, J.-V. (2013), "The cultural system and integrated reporting", International Business Review, Vol. 22 No. 5, pp. 828-838.

Guthrie, J., Manes-Rossi, F. and Orelli, R. L. (2017), "Integrated Reporting and Integrated Thinking in Italian Public Sector Organisations", Meditari Accountancy Research, Vol. 25 No. 4.

Haji, A. A. and Anifowose, M. (2016), "The trend of integrated reporting practice in South Africa: Ceremonial or substantive?", Sustainability Accounting, Management and Policy Journal, Vol. 7 No. 2, pp. 190-224.

Higgins, C., Stubbs, W. and Love, T. (2014), "Walking the talk(s): Organisational narratives of integrated reporting", Accounting, Auditing \& Accountability Journal, Vol. 27 No. 7, pp. 1090-1119.

Humphrey, C., O’Dwyer, B. and Unerman, J. (2017), "Re-theorizing the configuration of organizational fields: the IIRC and the pursuit of 'Enlightened' corporate reporting", Accounting and Business Research, Vol. 47 No. 1, pp. 30-63.

IIRC (2013), The International <IR> Framework. Available from: http://integratedreporting.org/resource/international-ir-framework/ [Accessed 17 May 2017].

IOD (2009), The King Code of Governance for South Africa (2009) and King Report on Governance for South Africa (2009) (King-III), Lexis Nexus South Africa, Johannesburg, South Africa.

IRCSA (2011), Integrated reporting and the integrated report. Discussion paper, Integrated Reporting Council of South Africa (IRCSA). Available from: www.sustainabilitysa.org [Accessed 31 July 2017].

Knauer, A. and Serafeim, G. (2014), "Attracting long-term investors through integrated thinking and reporting: A clinical study of a biopharmaceutical company", Journal of Applied Corporate Finance, Vol. 26 No. 2, pp. 57-64.

Lai, A., Melloni, G. and Stacchezzini, R. (2016), "Corporate sustainable development: Is 'Integrated Reporting' a legitimation strategy?", Business Strategy and the Environment, Vol. 25 No. 3, pp. 165-177.

Lai, A., Melloni, G. and Stacchezzini, R. (2017), "What does materiality mean to integrated reporting preparers? An empirical exploration", Meditari Accountancy Research, Vol. 25 No. 4.

Lee, K.-W. and Yeo, G. H.-H. (2016), "The association between integrated reporting and firm valuation", Review of Quantitative Finance and Accounting, Vol. 47 No. 4, pp. 1221-1250.

Lodhia, S. (2015), "Exploring the transition to integrated reporting through a practice lens: An Australian customer owned bank perspective", Journal of Business Ethics, Vol. 129 No. 3, pp. 585-598.

Lueg, K., Lueg, R., Andersen, K. and Dancianu, V. (2016), "Integrated reporting with CSR practices: A pragmatic constructivist case study in a Danish cultural setting", Corporate Communications: An International Journal, Vol. 21 No. 1, pp. 20-35.

Macias, H. A. and Farfan-Lievano, A. (2017), "Integrated reporting as a strategy for firm growth: Multiple case study in Colombia", Meditari Accountancy Research, Vol. 25 No. 4.

McNally, M.-A., Cerbone, D. and Maroun, W. (2017), "Exploring the challenges of preparing an integrated report", Meditari Accountancy Research, Vol. 25 No. 4.

Melloni, G., Stacchezzini, R. and Lai, A. (2016), "The tone of business model disclosure: An impression management analysis of the integrated reports", Journal of Management \& Governance, Vol. 20 No. 2, pp. 295-320.

Milne, M. J. and Gray, R. (2013), "W(h)ither ecology? The Triple Bottom Line, the Global Reporting Initiative, and corporate sustainability reporting", Journal of Business Ethics, Vol. 118 No. 1, pp. 13-29.

Mio, C., Marco, F. and Pauluzzo, R. (2016), "Internal application of IR principles: Generali's Internal Integrated Reporting", Journal of Cleaner Production, Vol. 139, pp. 204-218. 
Parrot, K. W. and Tierney, B. X. (2012), "Integrated reporting, stakeholder engagement, and balanced investing at American Electric Power", Journal of Applied Corporate Finance, Vol. 24 No. 2, pp. 27-37.

Perego, P., Kennedy, S. and Whiteman, G. (2016), "A lot of icing but little cake? Taking integrated reporting forward", Journal of Cleaner Production, Vol. 136, Part A, pp. 53-64.

PwC. 2015. Integrated reporting Where to next? Available: http://www.pwc.co.za/en/assets/pdf/integrated-reporting-survey-2015.pdf [Accessed 16 February 2016].

Serafeim, G. (2015), "Integrated reporting and investor clientele", Journal of Applied Corporate Finance, Vol. 27 No. 2, pp. 34-51.

Silvestri, A., Veltri, S., Venturelli, A. and Petruzzelli, S. (2017), "A research template to evaluate the degree of accountability of Integrated Reporting. A case study", Meditari Accountancy Research, Vol. 25 No. 4.

Solomon, J. and Maroun, W. (2012), "Integrated reporting: The influence of King III on social, ethical and environmental reporting", London, UK, ACCA

Steyn, M. (2014), "Organisational benefits and implementation challenges of mandatory integrated reporting: Perspectives of senior executives at South African listed companies", Sustainability Accounting, Management and Policy Journal, Vol. 5 No. 4, pp. 476-503.

Stubbs, W. and Higgins, C. (2014), "Integrated reporting and internal mechanisms of change", Accounting, Auditing \& Accountability Journal, Vol. 27 No. 7, pp. 1068-1089.

Zhou, S., Simnett, R. and Green, W. (2017), "Does Integrated Reporting Matter to the Capital Market?", Abacus, Vol. 53 No. 1, pp. 94-132. 